روئة لتسويق الإهكانات والمنشأت الرياضية بالمدارس الخاصة بمحافظات شمال الصعيد (دراسة تمليلية)

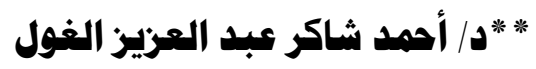

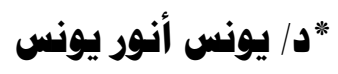

\title{
هقدهة البحث:-
}

تعد المدرسـة أحد الركائز الهامة التي يعتمد عليها المجتمع كالنوادي بأنوعها والسـاحات والمكتبات التي تسـتخدم كميادين للخدمة الموجهة في الترويح لإسـتثمار وقت الفراغ ، وتقام فيها خدمات مختلفة في أوجه الوان النشاط الرياضي والإجتماعي والثقافي، فأهميه المدرسـة لا تقف فقط عند تقايم النواحي العلمية ولكنها شـريك مع المجتمع في بناء مواطن شـــامل من كافة الجوانب لا ســـيما الجانب الرياضــــي

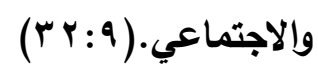

والأنشطة الرياضية بالمدارس هي مجموعة من الممارسات الحرة أو الموجهة من قبل المعلم والتي تســـهم في تنمية وتطوير مهارات الطفل، وتوفر لله مقومات الصـــة والســلامه الجســية والنفسـية والعقلية من أجل بناء مواطن صـالح، فهي تســـاهم في بناء الطقل وتثقيفة من خلال الانثــــة الرياضـــية والبدنية والحركية

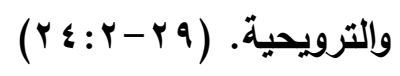

\footnotetext{
*هدرس بقسم الإدارة الرياضية - كلية التربية الرياضية- جاهعة بني سويف *** هدرس بقسم المناهج وطرق تدريس التربية الرياضية - جاهعة بني سويف
} 


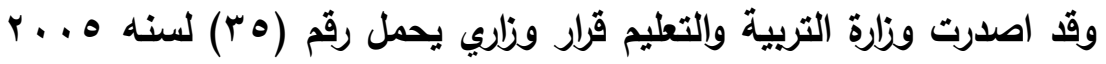
ونشراته التابعة لتجديد استثمار أنشطة المدارس عقب ساعات العمل الرسمية ويالعطلات متضمناً لاريع مجالات : الاول (نشاط تسويقي)، ثانياً (نشاط إنتاجي)، ثالثاً (أنثطة برمجيات)، رايعاً (نشاط خدمي)، وذلك من خلال:

- - استغلال مساحات المدرسة والابنية أفضل استغلال ويما لا يضر بالعملية

$$
\text { التعليمية.(• (1:1) }
$$

- يجوز للمواد التي تدرس ولهها منهج دراسي وتطبيقي أن تنضم الي مشروع المدرسة المنتجه بما يخدم تطوير وتفعيل المنهج الدراسي. - العمل علي استغلال الملاعب والادوات لتدريب الطلاب علي اللياقة البدنية والمهارات الحركية ويما يخدم الطلاب في دخول الكليات الرياضية والعسكرية

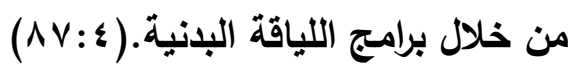

وفي الآونة الاخيره اصبح هناك تغيرات حادة في كافة المجالات لا سيما المجال الرياضي، واصبح لزاماً علي كافة القيادات الإدارية والمؤسسات والمنظمات الرياضية التعامل مع كافة التحديات التي فرضتها الثورة التكنولوجيه بمنظور شامل وواقعي، فالادارة الواعية هي التي تستطيع استيعاب المتغيرات المتسارعه فهي تعد مفتاح النجاح

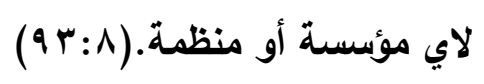

وقد تطور التسويق الرياضي من صناعة ضئيلة الي صناعة الملايين العديدة من الاولارات، وأسباب هذا النمو السريع وجود أوقات فراغ لاي الافراد ، لذلك أصبحت الرياضة والتسويق الرياضي أكثر أهمية في مجتمعنا، فتكنولوجيا الاتصال اعطي فرصة للجميع أن يشاهد ويتابع الأحداث الرياضية الجارية مما ساهم في رفع وعي المجتمع وادي الي اهتمام الجميع بالرياضة والتسويق الرياضي.(V. • · ) 
من خلال عمل الباحثين في المجال الأكاديمي والاشراف علي طلاب التربية العملية ، وايضاً من خلال العمل الخاص في ادارة الاندية والمنشأت الرياضية تبين لنا ضعف وندرة المنشأت مقارنة بعدد السكان، بالإضافة لوجود منشأت وإمكانات بالمدارس لا سيما المدارس الخاصة قيد البحث يمكن أن توظف بشكل جيا بما يدر دخلاً لتلك المدارس ومالكيها ويما يوفر للمجتمع منشأت وإمكانات جيده، وسعي الباحثين لمحاوية رصد بعض الاراسات التي تناولت تسويق واستغلال منشأت المدارس الرياضية ولكن تبين لنا أن هناك ندره في تلك الدراسات التي تتناول تسويق وتمويل المنشأت المدرسية الرياضية، وفي ظل توجهات الدولة الحديثة بتوفير كافة الخدمات للمواطنين بما فهم الخدمات الرياضية توجد توجهات لوزارة التربية والتعليم حديثاً لاستثمار الامكانات المادية والبشرية المتاحة لتوفير خدمات رياضية للطلاب والمجتمع المحيط خارج اليوم الدراسي مما دفع الباحثين لوضع روئة تسويقية يمكن من خلالها تسويق تلك الامكانات والمنشأت بما يدر دخلاً للمدرسة ويخدم المجتمع المحيط. أهداف البحث:-

يهدف البحث الي وضع روئة لتسويق الامكانات والمنشأت الرياضية بالمدارس الخاصة

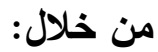

- - دراسة الواقع الحالي الامكانات والمنشأت الرياضية بالمدارس الخاصة. - - وضع روية لتسويق تلك الامكانات والمنشأت الرياضية.

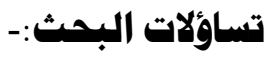

1. ماهي الامكانات والمنشأت الرياضية التي تمتلكها المدارس الخاصة. 


\section{مجلة بني سويف لعلوم التربية البلنية و الثرياضية مجلد (r) - العدد الساس ع}

r. ماهي بنود الروئة لتسويق الامكانات والمنشأت الرياضية بالمدارس الخاصة.

\section{خاهساً : هصطاحات البحث :}

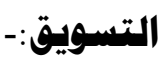

"مجموعة من الجهود والأنثطة المستمرة و المتكاملة التي تسهل وتصاحب انتقال الســلع والخدمات والأفكار من مصـادر إنتاجها إلي مشــتريها ويما يؤدي إلي تحقيق الأهداف والمنافع الاقتصادية والاجتماعية، للمستهلك والمنتج و المجتمع".( ( 9 9)

\section{التسويق الرياضي Sports Marketing}

"كل ما يحقق للنادي أو المؤسسـة الرياضية من موارد مالية عن طريق تبادل الأفكار والخدمات وإستثمار المنشـأت والملاعب والقاعات الرياضية وتبادل اللاعبين والمدربين لتأديه مهامها وتحقيق أهدافها وتنفيذ برامجها المختلفة" (0: ؟ ؛)

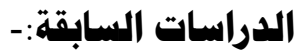

1 - "أسماء حبيب طه" (9 1 • r م) بعنوان "برنامج تربية رياضية مدرسية مطور كمصـدر لتمويل مؤسســـات التعليم قبل الجامعي"، يهـف البحث الي اقتراح برنامج تربية مدرسية تمثل مصدراً لتمويل برنامج التربية الرياضية المدرسية بمدارس محافظة بين سويف الحكومية، استخدمت الباحثة المنهج الوصفي، وضـــم مجتمع البحث مدارس محافظة بني ســـويف الحكومية وإلعاملين في مجال تدريس التربية الرياضسية، ويلغت عينة البحث باجمالي (• ب) مدرسـة و( • 1) أولياء أمور من كل مدرســـة وعدد ( . . ( طالب، وكانت اهم الاستخلاصات انه لاتوجد مصادر لتمويل الأنشطة الرياضية سوي المصدر الحكومي ، أن الأنشطة الرياضية لا تفي باحتياجات التلاميذ، لابد من تنوع الأنشطة الرياضية المختلفة. 
r ب بحث " أحمد ممدوح عبدالله" (9 1 • rم) بعنوان "القدرة التسـويقية التنافسية للملاعب الرياضـية بمحافظات شـمال الصـعيد" ويهـف البحث الي التعرف علي القدرة التسويقية التنافسية للملاعب الرياضية بمحافظات شمال الصعيد ، اسـتخدم الباحث المنهج الوصـفي (أسـلوب الدراســات المسـحية)، ومثل مجتمع البحث العاملين في مجال الملاعب المفتوحة التابعة لوزارة الثــباب والرياضية بالإضـافة الي مديري مديريات الثباب والرياضية ووكيل الثباب والرياضــة بمحافظات شــمال الصــعيد، تم اختيار العينة بشــكل عشـوائي

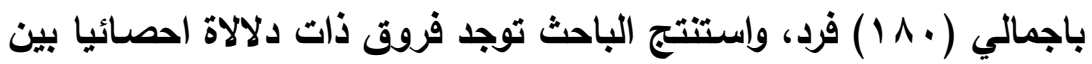
عينة المنيا والقيوم في واقع الإمكانات المادية والبثــــرية لاعم التســـويق التنـافســـي للملاعب المفتوحة وفي اتجـاه المنيـا ويرجع ذلك الي الدور الاكاديمية التي تقوم كليات التربية الرياضـــية في اعداد الخرجين وتاهيلهم

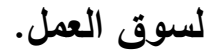

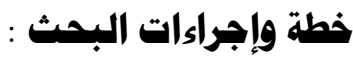

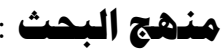

تم استخدام المنهج الوصفي ( أسلوب الدراسات المسحية ) بخطواته وإجراءاته وذلك لمناسبته لطبيعة وأهداف البحث.

\section{هجتهع البحث :}

يضم مجتمع البحث المدارس الخاصة بمحافظات شمال الصعيد (محافظة بني سويف - محافظة المنيا - محافظة الفيوم) وتضم محافظات شمال الصعيد عدد ( • (r) مدرسة بمحافظة بني سويف ، (11) مدرسة بمحافظة الفيوم، (Y Y ) مدرسة بمحافظة 
تم اختيار عينة البحث بالطريقة العشوائية من مجتمع البحث والجدول رقم (1) يوضح توصيف أفراد مجتمع وعينة البحث الأساسية والإستطلاعية كما يلي:

$$
\text { جدول (1) }
$$

توصيف أفراد مجتمع وعينة البحث الأساسية والإستطلاعية

\begin{tabular}{|c|c|c|c|c|}
\hline الثخصية & الاستطلاعية & الأساسينة & مجتمع & مجتمع البحث \\
\hline 9 & ir & $\leqslant 9$ & $7 \varepsilon$ & مديري ومالكي المدارس \\
\hline - & - & $r$ & $r$ & مديري المدارس بمديرية والتعليم \\
\hline 7 & 7 & 11 & $\mu$. & موجهي التربية الرياضية \\
\hline$r$. & ir & $v$. & 114 & معلمي التربية الرياضية \\
\hline - & - & $\Lambda$ & $\mathrm{V}$ & استثشاري التسويق \\
\hline - & ir & Or & $7 \leq$ & اداري المدارس الخاصة الماليين \\
\hline$\leqslant 0$ & $\leqslant 7$ & $1 \ldots$ & rAl & الإجمالى \\
\hline
\end{tabular}

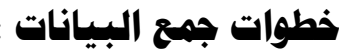

تم إستخدام العديد من الأدوات لجمع البيانات والمعلومات عن الدراسة قيد

$$
\text { البحث وسيتم عرضها فيما يلي: }
$$

تم تحليل المراجع والدراسات السابقة التي تناولت تسويق الامكانيات والانشطة الرياضية في كافة القطاعات كدراسة بغرض الوقوف علي سبل التسويق

$$
\text { ويناء عبارات ومحاور تخدم البحث الحالي . }
$$


تحليل الوثائق للإطلاع علي القواعد والقوانين الخاصة بالنواحي المالية للإمكانيات والمنشأت الرياضية وسبل الصرف عليها ومنها :-

-

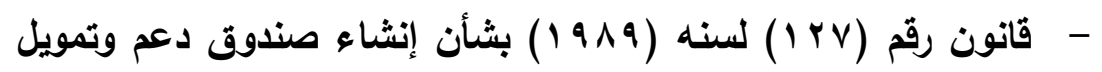

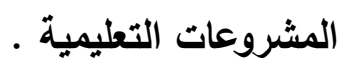

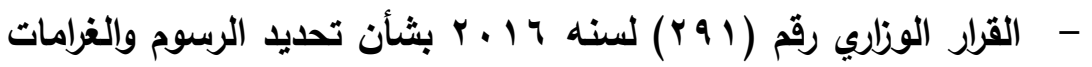
والاثتراكات مقابل الخدمات الاضافية التي تحصل من طلاب وطالبات المدارس الخاصة بمختلف المراحل التعليمية (المبلغ بالجنيه) . وجاءت اهم الاستخلاصات من تحليل الوثائق بعدم وجود اي نص أو قاعدة قانونية تسمح أو تمنع بشكل مباشر أو غير مباشر استخدام أو استغلال بعض المصادر المستحثثة في تسويق وتمويل الامكانيات والمنشأت الرياضية بثكل ذاتي بما يساهم في زيادة مصادر التمويل الذاتي للنشاط الرياضي المدرسي.

\section{r المابلة الشخصية المقننة :}

والتي تمت مع السادة موجهي التربية الرياضية ومديري ومالكي المدارس الخاصة بإجمالي عدد (0 ؛ ) بغرض التعرف علي رأيهم في أهم الحلول التسويقية المقترحة التي يمكن أن تصبح مصدراً لتمويل المدارس الخاصة من خلال استغلال كافة الامكانيات وإلمنشات الرياضية.

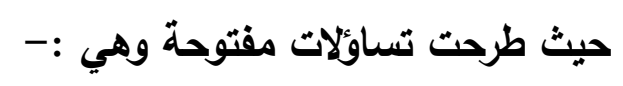

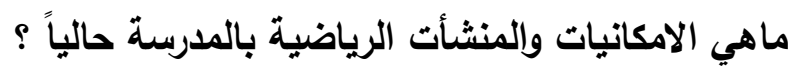
ما هي مصادر تمويل النشاط الرياضي المدرسي من حالياً؟ لإيات 


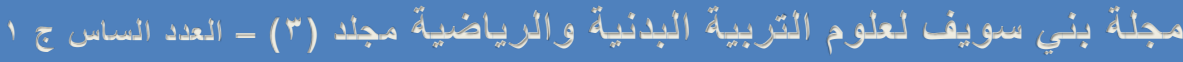

ما هي مقترحاتك لتسويق امكانيات ومنشأت المدرسة الرياضية؟

$$
\text { جدول (r) }
$$

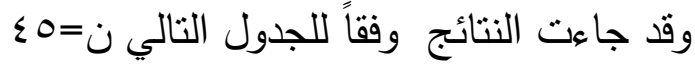

\begin{tabular}{|c|c|c|c|c|}
\hline \multicolumn{3}{|c|}{ النتائج وفقاً لأراء عينة المقابلة } & \multirow{2}{*}{ التساؤل } & \multirow{2}{*}{ b } \\
\hline نسبة الاتفاق & 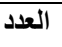 & النتيجة & & \\
\hline$\% 1 \ldots$ & $\varepsilon 0$ & - ملاعب خماسية & \multirow{5}{*}{ والمنشئات الأركانيات } & \\
\hline$\% \leq \varepsilon$ & $r \cdot$ & - حمام سباحة & & \\
\hline$\%$ & $\leqslant 0$ & - ملعب بلاط (كره يد- كرة سلة ) & & \\
\hline$\% 7 V$ & $r$. & - صالة جيم & & \\
\hline$\% \wedge 9$ & $\varepsilon$. & - كرات مختلفة الانواع & & \\
\hline$\% 1 \ldots$ & $\leqslant 0$ & - - تأجير واستغلال امكاتيات المدرسة & \multirow{2}{*}{ 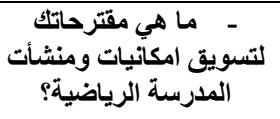 } & \\
\hline$\% 1 \ldots$ & $\leqslant 0$ & - - تقديم أنشطة ممولة ذاتياً & & \\
\hline$\% 1 \ldots$ & $\leqslant 0$ & 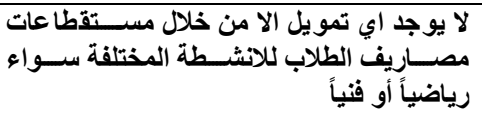 & 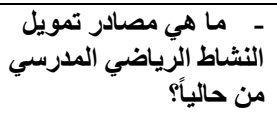 & \\
\hline
\end{tabular}

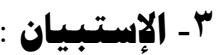

تم تحديد عدد من العبارات للإســتبيان والتي بلغ عدد ها ( ؛ه ) عبارة ، وقد تم مراعاة أن يكون للعبارة معنى محدد وأن تكون لغة كل عبارة صحيحة، والابتعاد عن العبارات الصعبة، وتجنب استعمال الكلمات التي تحمل أكثر من معنى.

المعاهلات العلمية لاستهمارة الاستبيان:-

- أولاً صدق المحتوى عن طريق استطلاع أري الخبراء :

تم عرض الاســتبيان في صـــورته المبائية على عدد (10) خبير في مجال الإدارة

الرياضـية والتسـويق الرياضــي وقوامهم (^) خبراء، وعدد ( ) خبراء في مجال الرياضــة

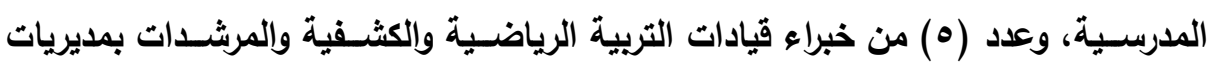

Beni-Suef Journal Of Physical Education And Sport Sciences

- 94 (B.J.P.E.S.S)

Website: https://obsa.journals.ekb.eg/

E-mail: journal. science@yahoo.com 


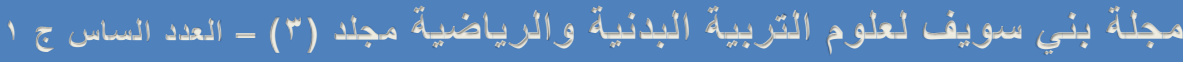

التربية والتعليم في محافظات شـمال الصـعيد وذلكك لإبداء الرأي في مدى مناسـبة العبارات للاستبيان، علي ان تتوافر في الساده الخبراء الثروط التالية:-

- - ألا يقل الخبير الأكاديمي من كلية التربية الرياضية قسم الادارة الرياضية والمناهج وطرق تدريس التربية الرياضية (رياضة مدرسية) عن درجة أستاذ مساعد. - - يفضــل أن يكون خبير قســـم المنـاهج وطرق التدريس ممن عملوا في قطاع اقتصاديات الرياضة أو الرياضة المدرسية ولهم باع في هذا المجال.

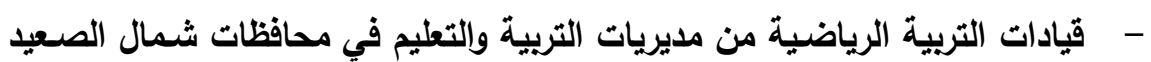
لا تقل سنوات خبرتهز عن خمس سنوات ويتجاوز عن المده اذا تواجد احدهم عمل في قطاع التسويق الرياضي. وقد تم إعداد اسـتمارة الاسـتبيان وعرض محاور بناءها علي الســاده الخبراء للتعرف علي واقع منشأت وإمكانات التربية الرياضية المدرسية وجائت المحاور علي النحو التالي : - - المحور الأول : الإمكانات المادية داخل المدارس. - المحور الثاني : الإمكانات البشرية داخل المدارس. - المحور الثالث : الخطط الحالية لتسويق الإمكانات والمنشأت داخل المدرسة. - - المحور الرابع : مشكلات تسويق امكانات ومنشأت المدرسة 
جدول (r)

يوضح النسبة المئوية لأراء الخبراء علي محاور الاستبيان ( ن = 10 )

\begin{tabular}{|c|c|c|c|c|c|c|}
\hline النهائية & عافارات تم & ت ع عبارفها & العبارات & أنسبة & التكرار & المحور \\
\hline$r$. & - & - & $r$. & $\% 1 \ldots$ & 11 & الإمكانات المادية داخل \\
\hline 1. & - & - & 1. & $\% 1 \ldots$ & 10 & الإمكانات البشرية داخل \\
\hline $1 \varepsilon$ & 1 & - & 14 & $\% 1 \ldots$ & 10 & الإمكانات والمالية لتسأت داخل \\
\hline 1. & 1 & - & 9 & $\% 1 \ldots$ & 10 & مشكلات تسويقت امكانات \\
\hline
\end{tabular}

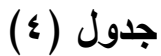

يوضح موافقة الساده الخبراء علي عبارات المحور الأول

\begin{tabular}{|c|c|c|c|c|c|c|c|}
\hline \% & موأفير & موافق & p & \% النسبة & غير موافق & هو افق & p \\
\hline$\% 1 \ldots$ & - & 10 & -11 & $\% 94$ & 1 & $1 \xi$ & -1 \\
\hline$\% 1 \ldots$ & - & 10 & $-I Y$ & $\% 1 \ldots$ & - & 10 & $\begin{array}{ll}-Y \\
\end{array}$ \\
\hline$\% 94$ & 1 & $1 \varepsilon$ & -14 & $\% 1 \ldots$ & - & 10 & $-r$ \\
\hline$\%^{\wedge \vee \vee}$ & r & 14 & $-1 \leqslant$ & $\%$ ^र & r & Ir & $-\varepsilon$ \\
\hline$\% 1 \ldots$ & - & 10 & -10 & $\% 94$ & 1 & $1 \xi$ & -0 \\
\hline$\% 1 \ldots$ & - & 10 & -17 & $\% 94$ & 1 & $1 \varepsilon$ & -7 \\
\hline$\% 1 \ldots$ & - & 10 & $-I V$ & $\% 1 \ldots$ & - & 10 & $-V$ \\
\hline$\% 1 \ldots$ & - & 10 & $-1 \wedge$ & $\% 1 \ldots$ & - & 10 & $-\wedge$ \\
\hline \multirow[t]{2}{*}{$\% 1 \ldots$} & - & 10 & -19 & $\% 1 \ldots$ & - & 10 & -9 \\
\hline & & & $-Y$. & $\% 1 \ldots$ & - & 10 & -1. \\
\hline
\end{tabular}

يتضح من جدول (؛ ) موافقة الساده الخبراء علي عبارات المحور الأول والذي يشمل الإمكانات المادية داخل المدارس الخاصـة بمدارس شـــال الصـعيد وتراوحت نسـبة 


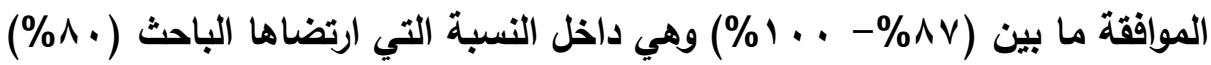
فأكثر.

$$
\text { جدول (o) }
$$

يوضح موافقة الساده الخبراء علي عبارات المحور الثاني

\begin{tabular}{|c|c|c|c|c|c|c|c|}
\hline \% & موافيق & موافق & م & ألنسبة & موافيق & موافق & p \\
\hline$\% 1 \ldots$ & - & 10 & -7 & $\% 1 \ldots$ & - & 10 & -1 \\
\hline$\% 1 \ldots$ & - & 10 & $-V$ & $\% 1 \ldots$ & - & 10 & $-Y$ \\
\hline$\% 94$ & 1 & $1 \varepsilon$ & $-\Lambda$ & $\% 1 \ldots$ & - & 10 & $-\Gamma$ \\
\hline$\% 1 \ldots$ & - & 10 & -9 & $\% 1 \ldots$ & - & 10 & $-\varepsilon$ \\
\hline$\% 1 \ldots$ & - & 10 & -1. & $\% 1 \ldots$ & - & 10 & -0 \\
\hline
\end{tabular}

يتضح من جدول (0) مواققة الساده الخبراء علي عبارات المحور الثاني والذي تشمل الإمكانات البثـرية داخل المدارس الخاصـة بمدارس شـمال الصـعيد وتراوحت نسـبة

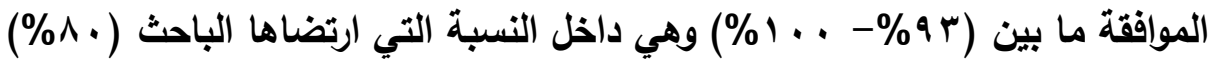

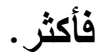

$$
\text { جدول (7) }
$$

\begin{tabular}{|c|c|c|c|c|c|c|c|}
\hline \% & مو غير & موافق & p & $\begin{array}{c}\text { النسبة } \\
\text { \% }\end{array}$ & غير موافق & مو افق & p \\
\hline$\%^{\wedge \wedge}$ & r & $1 \pi$ & $-\Lambda$ & $\% 1 \ldots$ & - & 10 & -1 \\
\hline$\% 1 \ldots$ & - & 10 & -9 & $\%^{94}$ & 1 & $1 \leqslant$ & $-Y$ \\
\hline$\% 1 \ldots$ & - & 10 & -1. & $\% 1 \ldots$ & - & 10 & $-r$ \\
\hline$\% 1 \ldots$ & - & 10 & -11 & $\% 1 \ldots$ & - & 10 & $-\varepsilon$ \\
\hline$\%$ & - & 10 & -14 & $\% 1 \ldots$ & - & 10 & -0 \\
\hline$\% 1 \ldots$ & - & 10 & -14 & $\%^{\wedge \vee}$ & r & 15 & -7 \\
\hline
\end{tabular}

يوضتح موافقة الساده الخبراء علي عبارات المحور الثالث

Beni-Suef Journal Of Physical Education And Sport Sciences

- 97 (B.J.P.E.S.S)

Website: https://obsa.journals.ekb.eg/

E-mail: journal. science@yahoo.com 


\begin{tabular}{l|l|l|l|l|l|l|l}
\hline & & & & $\% \wedge \vee$ & $r$ & $1 r$ & $-V$ \\
\hline \hline
\end{tabular}

يتضح من جدول (7) موافقة الساده الخبراء علي عبارات المحور الأول والذي يشمل الإمكانات المادية داخل المدارس الخاصة بمدارس شمال الصعيد وتراوحت نسبة

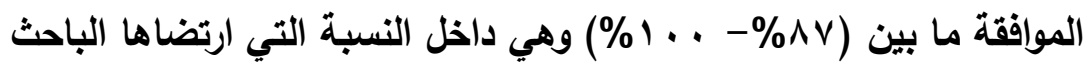

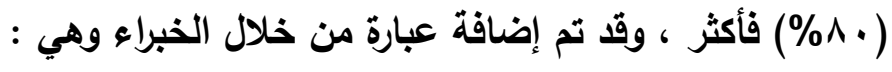

$$
\text { (v) ( }
$$

يوضح موافقة الساده الخبراء علي عبارات المحور الرابع

\begin{tabular}{|c|c|c|c|c|c|c|c|}
\hline \% & موافيق & موافق & p & \% & موافيق & موافق & p \\
\hline$\%$ & - & 10 & -7 & $\% 1 \ldots$ & - & 10 & -1 \\
\hline$\% 1 \ldots$ & - & 10 & $-V$ & $\% 94$ & - & 10 & $-Y$ \\
\hline$\% 1 \ldots$ & - & 10 & -1 & $\% 1 \ldots$ & - & 10 & $-r$ \\
\hline \multirow[t]{2}{*}{$\%$} & - & 10 & -9 & $\% 1 \ldots$ & - & 10 & $-\varepsilon$ \\
\hline & & & & $\%$ & - & 10 & -0 \\
\hline
\end{tabular}

يتضح من جدول (V) موافقة الساده الخبراء علي عبارات المحور الأول وإلذي يشمل الإمكانات المادية داخل المدارس الخاصـة بمدارس شـمال الصـعيد وتراوحت نسـبة

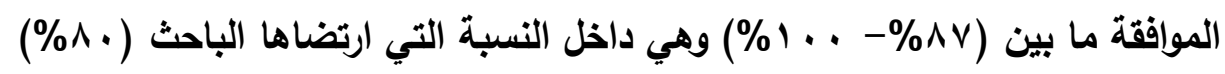
فأكثر ، وقد تم إضافة عبارة من خلال الخبراء وهي :

\section{ثانياً صدق الاتساق الداخلي للفقرات:}

للتأكد من اتساق الفقرات وارتباطها بالدرجة الكلية للاستبانة، استخدم الباحثون معامل الارتباط (بيرســون) بين الفقرة واللارجة الكلية للاسـتبانة، وكانت النتائج كما هي موضحة بالجدول رقم (^) كالتالي: 


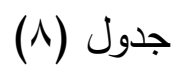

يوضح ارتباط الفقرات بالدرجة الكلية:

\begin{tabular}{|c|c|c|c|c|c|c|c|c|}
\hline الالالة & الارتباط معامل & b & الالالة & الارتباط معامل & b & الدلالة & الارتباط معامل & م \\
\hline دال & $\cdot, r \cdot v$ & ו & دال & r & -17 & دال & $\cdot, \leqslant 9$. & -1 \\
\hline دال &., $0 \wedge 0$ & $-r r$ & دال & $\cdot$, हा। & $-1 V$ & دال & $\cdot, \leqslant \vee q$ & $-r$ \\
\hline دال & $\cdot, \leqslant 94$ & -rr & دال & $\cdot, \Sigma \backslash T$ & -11 & دال &., $01 \mathrm{~V}$ & $-r$ \\
\hline دال & $\cdot, \Gamma q \varepsilon$ & $-r \varepsilon$ & دال & $\cdot, 0 \leq \leqslant$ & -19 & دال &., 0.9 & $-\varepsilon$ \\
\hline دال & $\cdot, \Gamma \wedge \top$ & ס & دال & $\cdot, \leqslant \leqslant$. & $-r$. & دال & $\cdot, \Sigma Y Y$ & -0 \\
\hline دال & $\cdot, \Sigma \wedge Y$ & $-r 4$ & دال & $\cdot, \leqslant 97$ & $-Y_{1}$ & دال & $\cdot, 0 \leqslant \wedge$ & -7 \\
\hline دال & $\cdot, \leqslant O Y$ & $-r V$ & دال & $\cdot, \leqslant \Psi \leqslant$ & $-r r$ & دال & $\cdot, \leqslant 9$. & $-V$ \\
\hline دال & $\cdot, 00 \mathrm{~V}$ & $-r \wedge$ & دال & • & $-r r$ & دال & $\cdot, \vee \wedge \vee$ & $-\Lambda$ \\
\hline دال & $\cdot, \varepsilon, 0$ & $-r q$ & دال & $\cdot, \Sigma T Y$ & $-Y \leqslant$ & دال & .,OH. & -9 \\
\hline دال & $\cdot, \leqslant \wedge \wedge$ & $-\varepsilon$. & دال & $\cdot, \leqslant \backslash 1$ & $-r o$ & دال & $\cdot, \Gamma \cdot r$ & -1. \\
\hline دال & • & $-\leqslant 1$ & دال & $\cdot, \Gamma \cdot r$ & $-Y \bar{T}$ & دال & $\cdot, Y 07$ & -11 \\
\hline دال & $\cdot$, TOM & $-\varepsilon Y$ & دال & $\cdot, \leqslant \backslash 1$ & $-Y V$ & دال & $\cdot, 0 \leq 9$ & $-1 Y$ \\
\hline دال & $\cdot, r \vee q$ & $-\varepsilon \psi$ & دال & $\cdot, r O r$ & $-r \wedge$ & دال & $\cdot, r q \wedge$ & -14 \\
\hline \multirow[t]{2}{*}{ دال } & $\cdot, \Gamma \wedge V$ & $-\leqslant \leqslant$ & دال &., 090 & $-r q$ & دال & $\cdot, r V Y$ & $-1 \varepsilon$ \\
\hline & & & دال & זTT, & $-r$. & دال & r & -10 \\
\hline
\end{tabular}

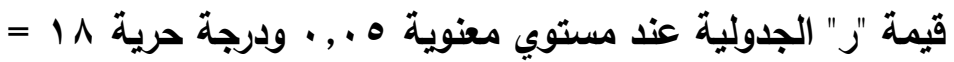

$\cdot, \mathrm{rV \Lambda}$

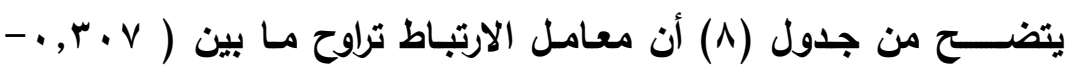

VAV

بمجموع الاستمارة مما يال علي صدق الاتساق الداخلي لعبارات الاستمارة 


\section{ثبات الاستهمارة:}

للتحقق من ثبات الاسـتمارة اسـتخدم الباحثون معامل ألفا كرو نباخ للثبات وكان معامل الثبات الكلي (AV ) وهو معامل ثبات جيد. كما أوجد الباحث ثبات المحاور كلاً على حدة فكانت كمـا هي مبينـة

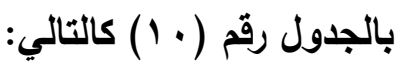

جدول(9)

يوضح معامل الثبات لمحاور الاستبانة

\begin{tabular}{|c|c|}
\hline معامل الثبات & المحور \\
\hline$\cdot, V Y Y$ & الإمكانات المادية داخل المدارس \\
\hline$\cdot, 110$ & الإمكانات البشرية داخل المدارس \\
\hline$\cdot, \wedge \leq 1$ & الخطط الحالية لتسويق الإمكانات و المنشأت داخل \\
\hline$\cdot, \vee \vee 97$ & مشكلات تسويق امكانات ومنشأت المدرسة \\
\hline
\end{tabular}

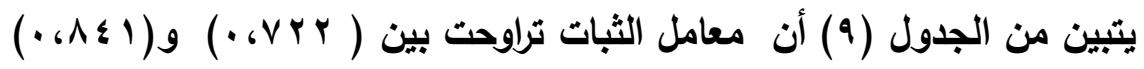
لعبارات المحاور، امـا مجموع المحاور فقد بلغ (·^، ·) وتعتبر هذه القيم عالية مما يدل على ان الثبات مرتفع للعبارات وكذلك مجموع المحاور تتمتع بثبات مقبول، ويهذا يكون الباحثون قد تحقق من صــــق وثبات الاســــمارة وتكون جاهزة للتطبيق.

\section{الأسلوب الإحصائي المستخدم :}

بعد جمع البيانات وجدولتها تم معالجتها إحصـائياً ، ولحسـاب نتائج البحث استخدم الباحثون الأساليب الإحصائية الآتية : 
1- - - معامل الأرتباط بيرسون

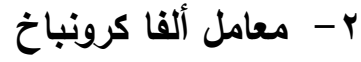

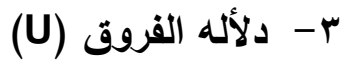

وقد ارتضي الباحثون مستوى دلالة عند مستوى (ه ., •) ، كما استخدم الباحثون

برنامج Spss لحساب المعاملات الإحصائية .

عرض وهناقشة النتائج: -

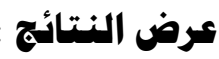

سوف يقوم الباحثون بعرض نتائج البحث علي النحو التالي :.

1. ماهي الامكانات والمنشأت الرياضية التي تمتلكها المدارس الخاصة. r. ماهي بنود الروية لتسويق الامكانات والمنشأت الرياضية بالمدارس الخاصة.

$$
\text { جدول (1.) }
$$

التكرار والنسبة المئوية واللدرجة المقدرة والوزن النسبي لاستجابات عينة البحث

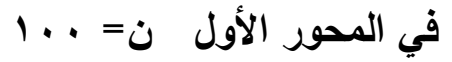

\begin{tabular}{|c|c|c|c|c|c|c|}
\hline \multirow{2}{*}{ النسي } & \multirow{2}{*}{ المقرة الدرة } & \multicolumn{2}{|c|}{$y$} & \multicolumn{2}{|c|}{ نعم } & \multirow{2}{*}{ العبارة } \\
\hline & & نسبه & عدد & نسبة\% & عدد & \\
\hline ro,o. & $\pi$. & $\% \wedge$. & A. & $\%$ r. & r. & 1 \\
\hline $1 \ldots, \ldots$ & r.. &,,$\cdots$ & - & $\% 1 \ldots$ & $1 \cdots$ & r \\
\hline $1 \ldots, \ldots$ & r.. &,,$\cdots$ & - & $\% 1 \ldots$ & $1 \cdots$ & $r$ \\
\hline $1 \ldots, \cdots$ & $r \ldots$ & $\cdot, \cdots$ & - & $\% 1 \ldots$ & $1 \cdots$ & $\varepsilon$ \\
\hline$\varepsilon 9, \cdots$ & 147 & $\% 7 \varepsilon$ & $7 \varepsilon$ & $\%$ & $r 7$ & 0 \\
\hline $1 \ldots, \cdots$ & r.. & $\cdot, \cdots$ & - & $\% 1 \ldots$ & $1 \ldots$ & 7 \\
\hline $1 \ldots, \ldots$ & $r \ldots$ &,$+ \cdots$ & - & $\% 1 \ldots$ & $1 \ldots$ & V \\
\hline$\Lambda 1, \cdots$ & 17. & $\%$ \&. & $\varepsilon$. & $\% 7$. & 7. & $\Lambda$ \\
\hline $1 \ldots, \ldots$ & $r \ldots$ & $\cdot, \cdots$ & - & $\% 1 \ldots$ & $1 \ldots$ & 9 \\
\hline $1 \ldots, \ldots$ & $r \ldots$ &,$+ \cdots$ & - & $\% 1 \ldots$ & $1 \ldots$ & 1. \\
\hline $1 \cdots, \cdots$ & $r \ldots$ & $\cdot, \cdots$ & - & $\% 1 \ldots$ & $1 \ldots$ & 11 \\
\hline $1 \ldots, \ldots$ & r.. & $\cdot, \cdots$ & - & $\% 1 \ldots$ & $1 \cdots$ & IT \\
\hline $1 \ldots, \ldots$ & Y.. & $\cdot, \cdots$ & - & $\% 1 \ldots$ & $1 \ldots$ & $r$ \\
\hline
\end{tabular}

Beni-Suef Journal Of Physical Education And Sport Sciences

- 1... (B.J.P.E.S.S)

Website: https://obsa.journals.ekb.eg/

E-mail: journal.science@yahoo.com 


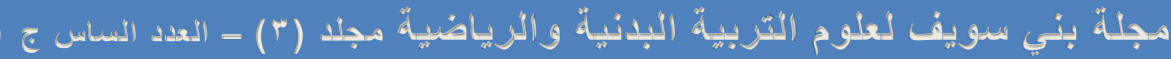

\begin{tabular}{|c|c|c|c|c|c|c|}
\hline $1 \ldots, \ldots$ & r.. & $\cdot, \cdots$ & - & $\% 1 \ldots$ & $1 \ldots$ & $1 \varepsilon$ \\
\hline$\cdots, \ldots$ & $r \ldots$ & $\cdot, \cdots$ & - & $\%$ & $1 \cdots$ & 10 \\
\hline $1 \cdots, \cdots$ & r.. & $\cdot, \cdots$ & - & $\% 1 \ldots$ & $1 \ldots$ & 17 \\
\hline $1 \ldots, \cdots$ & r.. & $\cdot, \cdots$ & - & $\% 1 \ldots$ & $1 \ldots$ & IV \\
\hline $1 \ldots, \ldots$ & r.. & $\cdot, \cdots$ & - & $\% 1 \ldots$ & $1 \ldots$ & 11 \\
\hline $1 \cdots, \cdots$ & $r \ldots$ & $\cdot, \cdots$ & - & $\% 1 \ldots$ & $1 \cdots$ & 19 \\
\hline $1 \cdots, \ldots$ & $r \ldots$ & $\cdot, \cdots$ & - & $\% 1 \ldots$ & $1 \ldots$ & $r$. \\
\hline
\end{tabular}

تثــير نتائج جدول ( • 1) الي التكرار والنسـبة المئوية والدرجة المقرة والوزن

النسبي حيث اثـارت النتائج في المحور الأول بنسبة . . 1\% عدا عبارة رقم (1) والتي تنص علي يوجد بالمدرســة ملعب كرة قدم قانوني، وقد حصــلت علي نســبه

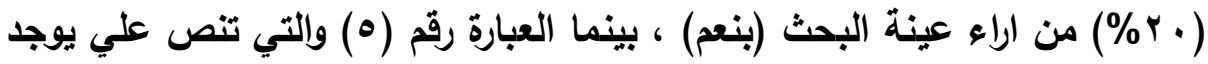
بالمدرســة حمام سـباحه، حصـلت علي نسـبة (؟ب) من اراء عينة البحث ، بينما العبارة رقم (^) والتي تنص علي يوجد بالمدرسـة مســاحات خضـراء اخري (تصـلح لرياضة العاب القوي) بجانب ملاعب الكرات، حصلت علي نسبة ( • ؟) من اراء عينة

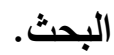

\section{جدول (11)}

التكرار والنسبة المئوية والدرجة المقرة والوزن النسبي لاستجابات عينة البحث

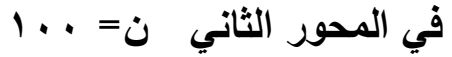

\begin{tabular}{|c|c|c|c|c|c|c|}
\hline \multirow{2}{*}{ الوزن النسبي } & \multirow[t]{2}{*}{ الدرجة المقدرة } & \multicolumn{2}{|c|}{ ע } & \multicolumn{2}{|c|}{ نعم } & \multirow{2}{*}{ رقم العبارة } \\
\hline & & نسبه & عدد & نسبة\%\% & عدد & \\
\hline $1 \cdots, \cdots$ & r.. & $\cdot, \cdots$ & - & $\% 1 \ldots$ & $1 \ldots$ & 1 \\
\hline$\leqslant 0, \ldots$ & TrY & $\% \curlyvee \wedge$ & 71 & $\%$ \%r & Tr & $r$ \\
\hline $1, \ldots$ & $1 \cdots$ & $\% 1 \ldots$ & $1 \cdots$ & $\cdot, \cdots$ & - & $r$ \\
\hline $1, \ldots$ & $1 \ldots$ & $\% 1 \ldots$ & $1 \ldots$ & $\cdot, \cdots$ & - & $\xi$ \\
\hline $1, \ldots$ & $1 \ldots$ & $\% 1 \ldots$ & $1 \ldots$ & $\cdot, \cdots$ & - & 0 \\
\hline$r 0,0$. & Ir. & $\%{ }^{\wedge}$ & $\Lambda$. & $\%$ \%. & $r \cdot$ & 1 \\
\hline$\leq \vee, \ldots$ & $1 \% 0$ & $\% 70$ & 70 & $\%$ ro & ro & $\mathrm{V}$ \\
\hline $09, \ldots$ & $1 \leq 1$ & $\% 09$ & 09 & $\%$ \% & $\leqslant 1$ & $\Lambda$ \\
\hline$\leqslant 0,0$. & ir. & $\% \vee$ & v. & $\%$ & $r$. & 9 \\
\hline $1,, \cdots$ & $1 \cdots$ & $\% 1 \ldots$ & $1 \cdots$ & $\cdot, \cdots$ & - & 1. \\
\hline $1, \ldots$ & $1 \ldots$ & $\% 1 \ldots$ & $1 \ldots$ & $\cdot, \cdots$ & - & 11 \\
\hline $1+, \cdots$ & $1 \ldots$ & $\% 1 \ldots$ & $1 \ldots$ & $\cdot, \cdots$ & - & IY \\
\hline
\end{tabular}

Beni-Suef Journal Of Physical Education And Sport Sciences

- 1.1: (B.J.P.E.S.S)

Website: https://obsa.journals.ekb.eg/

E-mail: journal.science@yahoo.com 
تثـير نتائج جدول (11) الي التكرار وإلنسـبة المئوية والارجة المقدرة والوزن النسبي حيث جاءت جميع العبارات ب (لا) عدا العبارة رقم (1) حصـلت علي نسـبة . . . 1 من (نعم) كاراء لعينة البحث وتراوحت موافقة عينة البحث في ابداء ارائهم

$$
\text { (بنعم) من ( . . . - . . 1\%\%) فجائت جميع العبارات في اتجاه (لا). }
$$

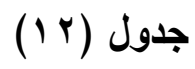

التكرار وإلنسبة المئوية والدرجة المقدرة والوزن النسبي لاستجابات عينة البحث

\begin{tabular}{|c|c|c|c|c|c|c|}
\hline \multirow{2}{*}{ الوزن النسبي } & \multirow[t]{2}{*}{ الدرجة المقدرة } & \multicolumn{2}{|c|}{ V } & \multicolumn{2}{|c|}{ نعم } & \multirow{2}{*}{ رقم العبارة } \\
\hline & & نسبه & عدد & نسبة\%\% & عدد & \\
\hline $1 \ldots, \cdots$ & $r \ldots$ & $\cdot, \cdots$ & - & $\% 1 \ldots$ & $1 \ldots$ & 1 \\
\hline$\leqslant 0, \ldots$ & TrY & $\% 4 \wedge$ & 71 & \%rr & $r r$ & r \\
\hline $1, \ldots$ & $1 \ldots$ & $\% 1 \ldots$ & $1 \ldots$ & $\cdot, \cdots$ & - & $r$ \\
\hline $1, \ldots$ & $1 \ldots$ & $\% 1 \ldots$ & $1 \ldots$ & $\cdot, \cdots$ & - & $\varepsilon$ \\
\hline $1, \ldots$ & $1 \ldots$ & $\% 1 \ldots$ & $1 \ldots$ & $\cdot, \cdots$ & - & 0 \\
\hline$r 0,0$. & Tr. & $\%{ }^{\wedge}$ & $\Lambda$. & $\%$ \%. & $r \cdot$ & 7 \\
\hline$\leq V, \ldots$ & iro & $\% 70$ & 70 & $\%$ ro & ro & V \\
\hline $1, \ldots$ & $1 \ldots$ & $\% 1 \ldots$ & $1 \ldots$ & $\cdot, \cdots$ & - & $\Lambda$ \\
\hline$r \Delta, 0$. & Tr. & $\%$ & $\Lambda$. & $\%$ \%. & $r \cdot$ & 9 \\
\hline
\end{tabular}

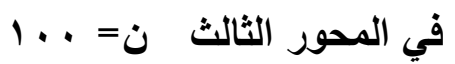

تثسير نتائج جدول (r r ) الي التكرار والنسبة المئوية والدرجة المقدرة والوزن النسـبي حيث جاءت جميع العبارات ب (لا) عدا العبارة رقم (1) حصـلت علي نسـبة . . . 1\% من (نعم) كاراء لعينة البحث وتراوحت موافقة عينة البحث في ابداء ارائهم

$$
\text { (بنعم) من ( . ., - . . 1\%\%) فجائت جميع العبارات في اتجاه (لا). }
$$

$$
\text { جدول (1T) }
$$

\begin{tabular}{|c|c|c|c|c|c|c|}
\hline \multirow{2}{*}{ الوزن النسبي } & \multirow[t]{2}{*}{ الارجة المقدرة } & \multicolumn{2}{|c|}{ ע } & \multicolumn{2}{|c|}{ نعم } & \multirow{2}{*}{ رقم العبارة } \\
\hline & & نسبه & عدد & نسبة\% & عدد & \\
\hline Ar, . & $17 \varepsilon$ & $\% 44$ & 49 & $\%$ \% & $7 \varepsilon$ & 1 \\
\hline $94,0$. & 194 & $\% \vee$ & v & $\%$ \% & 94 & $r$ \\
\hline $9 \leqslant, \ldots$ & 111 & $\%$ Ir & Tr & $\% \wedge \wedge$ & $\Lambda \Lambda$ & $r$ \\
\hline$\leqslant \wedge, \ldots$ & $1 \leqslant$. & $\% 4$. & 7. & $\%$ «. & $\varepsilon$. & $\varepsilon$ \\
\hline
\end{tabular}

التكرار والنسبة المئوية والدرجة المقرة والوزن النسبي لاستجابات عينة البحث

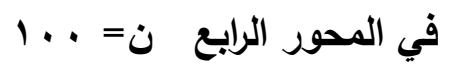

Beni-Suef Journal Of Physical Education And Sport Sciences

- 1.r. (B.J.P.E.S.S)

Website: https://obsa.journals.ekb.eg/

E-mail: journal. science@yahoo.com 
مجلة بني سويف لعلوم التربية البلنية والكرياضية مجلد (ب) - العدد النساس ج ا

\begin{tabular}{|c|c|c|c|c|c|c|}
\hline$\wedge \leq, \ldots$ & 171 & \%rr & rr & $\% \curlyvee \wedge$ & 71 & . \\
\hline $9 \leq, \ldots$ & 111 & $\%$ Ir & Ir & $\% \wedge \wedge$ & $\Lambda \Lambda$ & 1 \\
\hline$\Lambda_{r}, \ldots$ & $17 \varepsilon$ & \% & rq & $\% ч \leq$ & $7 \varepsilon$ & v \\
\hline 人ч,.. & IVY & $\%$ \% & YA & $\% \vee r$ & VY & $\wedge$ \\
\hline Ar,, & $17 \varepsilon$ & \%rч & 47 & \%४ & $7 \varepsilon$ & 9 \\
\hline $9 \wedge, \ldots$ & 197 & $\% \leftleftarrows$ & $\xi$ & $\% 94$ & 94 & 1. \\
\hline
\end{tabular}

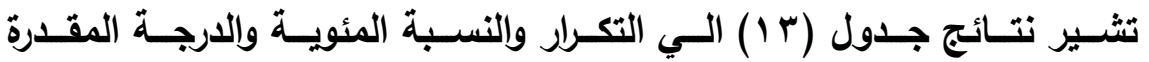

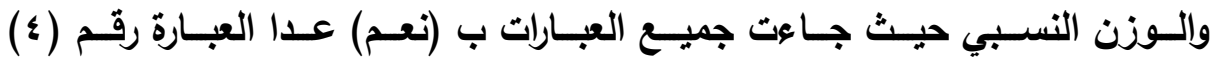

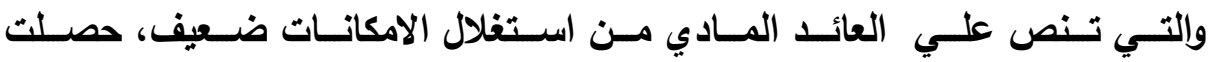
علـي نسـبة ، ؛ \% مـن (نعـم) كـاراء لعينـة البحـث وتراوحت موافقـة عينـة البحـث

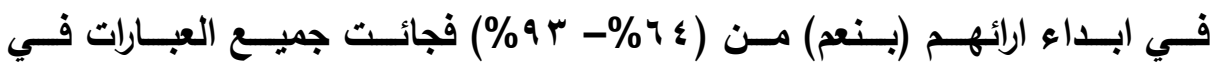
اتجاه (نعم).

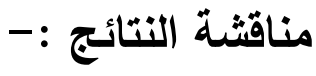

فـي ضـوء تحليـل النتـائج السـابقة وفـي حـدود نتـائج المقابلــة الشخصـية التـي أجريـت مـع بعض مـن مجتــع البحـث توصـل البـاحثين الـي النتـائج التـي تصف الواقع الحالي:التساؤل الأول ا ـ ماهي الامكانات والمنشأت الرياضية التي تمتلكها المدارس الخاصة. مـن خـلال المقابلـة الثخصـية التـي اجراهـا البـاحثون مـع عـد مـن عيــة البحـث ، اكـدت علـي وجـود بعض الإمكانـات والمنشـأت الرياضـية الهامـة داخـل المــارس الخاصــه ، كالملاعـب الخماسـية بانواعهــا الـبلاط والنجيـل ، تنــوع وجـود الكـرات مختلفــة الاحجــام لانشــطة رياضـية مختلفــة ، بعـض المــارس الخاصة توجد بها حمامات سباحة تعليمية. 
ويــالنظر الــي جــول ( • 1) يتبـين للبـاحثين أن نسـبة ( . 1 (\%) مسن

عينـة البحث لــيها ملعب خماسـي كره قدم وملاعب جماعيـة لكره اليـــ والطـائرة

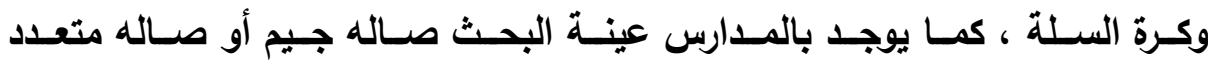
الاســتخدام ، وتعـدـد الأدوات وإلكـرات مختلفــة الاحجــام والأنثــطة كـــرة القــدم

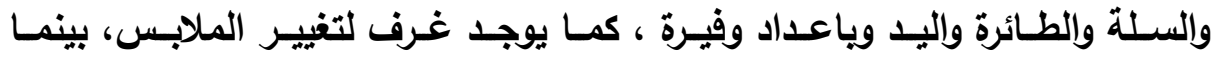
تفتقـر غالبيـة المــارس الــي ملعـب كـره قـدم قـانوني ، وحمــام سـباحة تعليمسي ويعـض المــارس بنسـبة قليــة لا تتناسـب معهـا رياضــة العـاب القـوي لصــر حجـم المســاحة الخضــراء والتــي تحتاجهــا رياضــة العـاب القـوي نظـراً لطبيعـة أنشطتها.

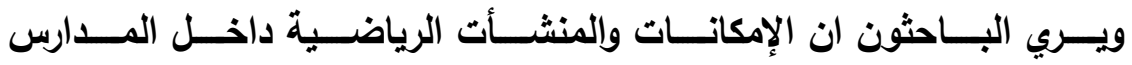
الخاصــة كنـز يحتـــاج الـي اسـتثماره ،فــن خــلال عرضــنا الســابق نســطيع أن نـــكر أن هـذا الكنـز الرياضــي يحتــاج الــي خارطـه صـحيحة يمكـن مـن خلالهـا

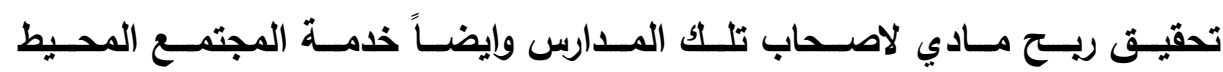
رياضياً، وهذا ما تتفق عليه دراسة "أحمد السيد متولي" (؛ 1 • بم)(1 )

ويتضــح مـن جــدول (11) ضـــف الكـــوادر الثــبابية مــن المـــربين

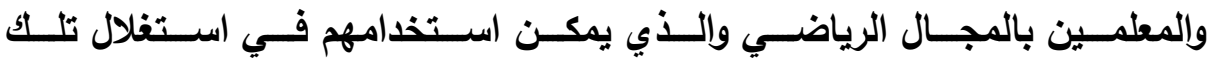

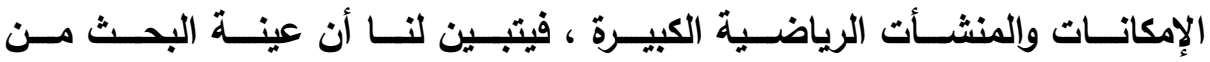
المــارس الخاصـة لا يتـوافر لـلـيهم سـوء معلمـين تربيـة رياضـية معينين ، ومـن

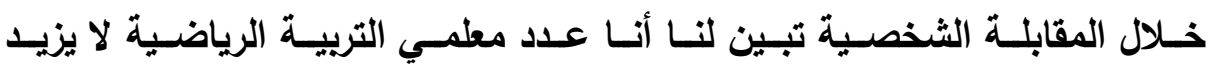

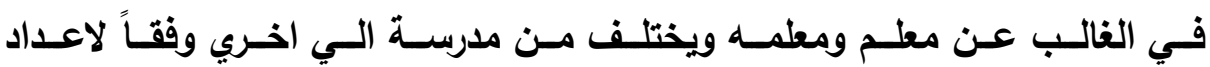


فالمــارس الخاصــة رغــم وجـود ملاعـب عديـــة ومنشــأت وأدوات مختلفــة

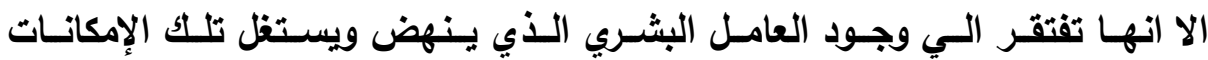
والمنشأت بما يدر دخلاً لتلك المنشأت ويخدم القطاع المجتمعي المحيط. ويعـزو البـاحثون هـذا الــي عـدم وجـود خطـط اسـتثمارية فـي الأنثـطة

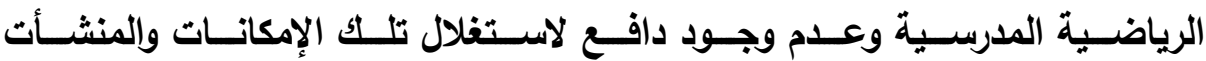
بشكل مناسب.

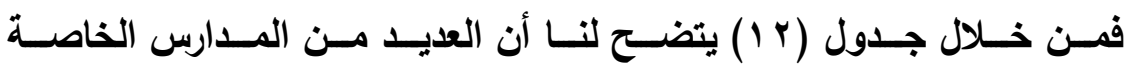

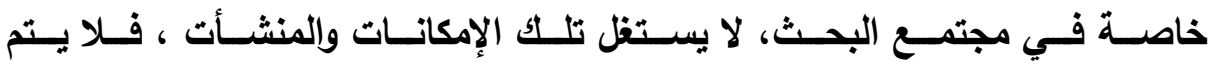
تـأجير تلــك الملاعب خـارج اليـوم الدراسـي للمجتمـع المحيط، ولا تقيم المــارس أنثــطة مجتمعيـة يـتثم مسن خلالهـا اسـتفلال تلــك المنشــأت الرياضـية والأدوات، ولا يســــح باســتغلال اســوار المـــارس ســواء الاخليــة أو الخارجيـة للتــرويج للانثـطة المختلفـة ، كمـا أنـه لا توجــ شـراكات مـع المجتمـع المحسيط لاسـتغلال الإمكانـات والمنشــات الرياضـية، ومسن خـلال هــا المحسور الـذي اظهـر ضــف

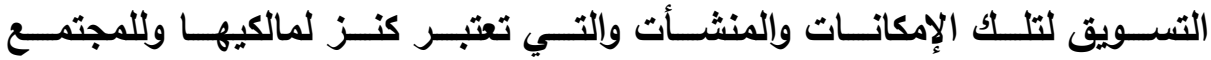
المحيط ، يعزو البـاحثون هـا الـي عدم وجـود خطط سـابقة أو حاليـة لتسـويق

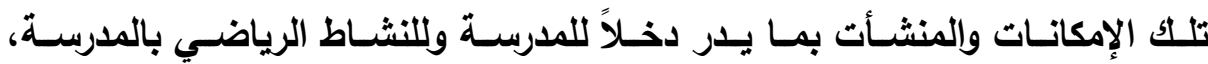

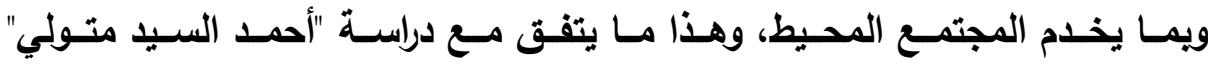

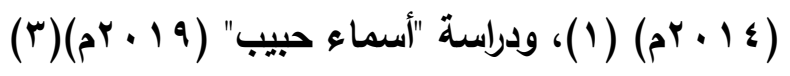

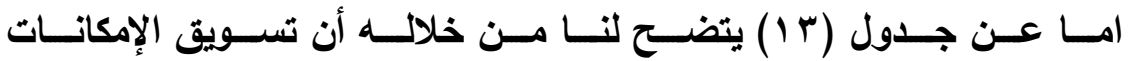

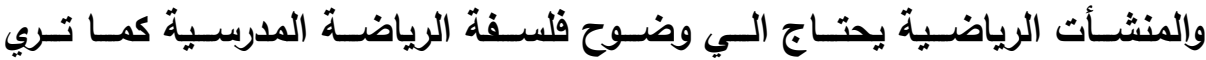

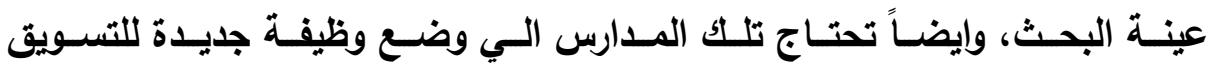


لتلـــ الإمكانـات والمنشـأت بشـكل سـليم ، بينمـا يـري عـدـ كبيـر بـأن إمكانــات المدرســة يفـي فقـط باحتياجـات الطـلاب المقيـدين بالمدرسـة بالمراحلـل المختلفـة ، امــا الثــريحة الكبـرى مـن عينـة البحـث تـري أن الفكـر التســويقي للرياضــة المدرسية ليست محبذه في الوطن العربي .

ومسن خـلال عـرض نتـائج الواقـع الحسالي للامكانــات والمنشــات الرياضـية سـواء الماديـة أو البثـرية، وايضــاً مـن خـلال عـرض نتـائج الدراســات السـابقة

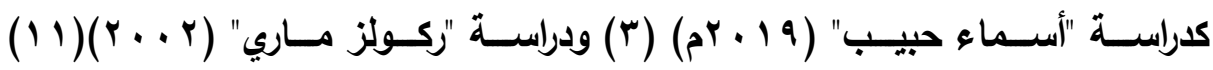

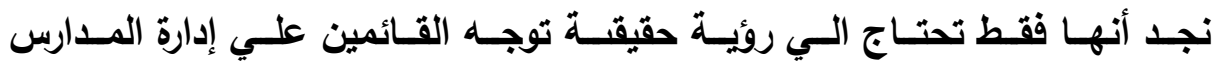

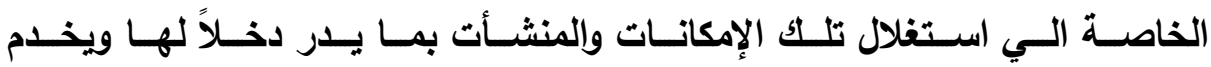

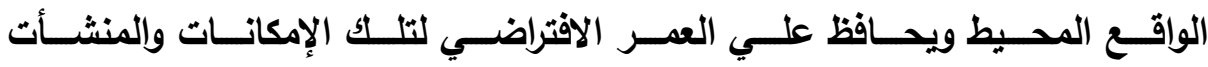
الرياضية.

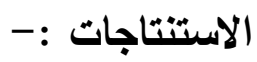

فـي ضـوء أهــاف وتشــاؤلات البحـث ومـن خــلال المقابلـة الثخصـية وإسـتمارة الاستبيان والتي اعدها الباحثان يمكن صياغه الاسنتاجات التالية :- - امـتلاك المــدارس الخاصــة إمكانــات ومنشــأت كبيـره بخــلاف المــارس الحكومية.

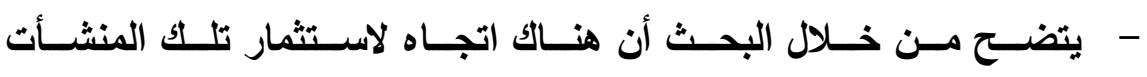
والإمكانـات ولكـن مـالكي المــارس يحتــاجوا الــي اسـتراتيجية إدارة بمـا يضمن الحفاظ علي الإمكانات والمنشأت. 
- أظهـرت نتـائج البحـث ان لـيس هنـاك فلســفة واضـــة للتسـويق فـي

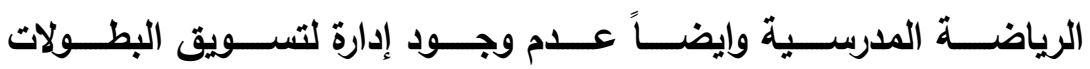
والمنافــات الرياضـية المدرسية فـي الهيكـل التنظيمسي لـوزارة التربيـة

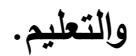

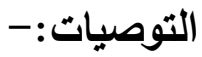

- العمل علي تطبيق خطة تسويق الإمكانات والمنشأت الرياضية المدرسية المقترحة.

- عرض خطوات التسويق للامكانات والمنشأت الرياضية علي مالكي المدارس

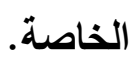

- أن يكون ضمن الهيكل الوظيفي مسئول عن التسويق الرياضي المدرسي - حث وسائل الاعلام علي التركيز علي الإمكانات الرياضية بالمدارس بصفة عامة والمدارس بصفة خاصة يمكن استغلالهما خارج اليوم الدراسي بما يضمن خدمة قطاع كبيرة من المجتمع. - تأجير أماكن علي جدران الحوائط وارضيات الملاعب لعرض إعلانات المعلنين - الصيانة المستمرة للامكانات والمنشأت الرياضية المدرسية. - العمل علي وضع منهاج تربية رياضية يساهم في بناء الطلاب ويعزز من حب الطالب للنشاط الرياضي. ماهي بنود روئة تسويق الامكانات والمنشأت الرياضية بالمدارس الخاصة. في ضوء ما تم مناقشته من واقع حالي لإمكانات ومنشات المدارس الخاص ومن خلال اهداف ومشكلة البحث يضح الباحثون في 
الاستنتاجات خطة لتسويق تلك الإمكانات والمنشأت الرياضية بالمدارس

الخاصة:-

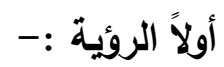

الوصول الي أسلوب أمثل في تسويق الإمكانات والمنشأت الرياضية

بالمدارس الخاصة

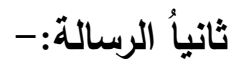

المدارس الخاصة تعمل جاهده علي خدمة المجتمع المحيط تعليمياً

وتريوياً ورياضياً، فهي تقدم خدماتها للمجتمع المحيط بما تمتلكه من

$$
\text { إمكانات ومنشأت مختلفة تجذب أولياء الأمور }
$$

نقاط القوة :

$$
\text { - - منشأت حديثة وجيدة. - أدوات عديدة ومتددة. }
$$

- دائماً موقع جغرافي جيد مناسب للمجتمع المحيط.

نقاط الضعف:

$$
\begin{aligned}
& \text { - علدم وجود خطط تسويقية. } \\
& \text { - عدم استغلال الإمكانات والمنشأت الجيدة. } \\
& \text { - } \\
& \text { أهداف خطة التسويق:- }
\end{aligned}
$$$$
\text { - استغلال ملاعب المدرسة خارج اليوم المدرسي. }
$$$$
\text { - استغلال الأدوات المتعددة }
$$ 


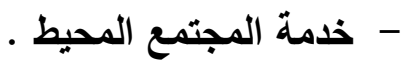

- الإمكانات والمنشأت تدر دخلاً للصرف علي النشاط الرياضي المدرسي وإيضاً تدر دخلا لمالكي تلك المدارس.

توصل الباحثون الي خطة لتسويق الإمكانات والمنشأت الرياضية بالمدارس الخاصة

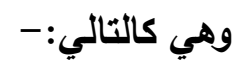

أولاً فلسفة الخطة المقترحة:

تقوم فلسفة الخطة المقترحة علي عده نقاط أهمها

1- اقتناع الساده مديري المدارس ومالكي المدارس الخاصة بأهمية التسويق

لمنشأتهم وامكاتتهم المادية والبشرية.

ץ- البدء في تحسين العيوب وحل المشكلات وإلعقبات التي تظهر قبل وإثناء ويعد

التسويق بصفة مستمرة.

وترتكز فلسفة الخطة المقترحة علي العديد من المرتكزات أهمها:-

أن خطة التسويق عنصراً من عناصر الخطة التجارية الاستراتيجية العامة لأي منشأه حيث تعبر عن أمال المنشأه وتطلعاتها نحو تحقيق النجاح في السوق، ويالتالي تصبح تلك الخطة بمثابة الموجه العام لتحقيق اهداف المنشاة . تقوم خطة التسويق علي تحديد الخدمة أو المنتج ومواصفاته وسعره ووسائل الإعلان والترويج المتصلة به ومكان وقنوات توزيعه.

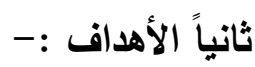
تهذف الخطة الي تسويق الإمكانات والمنشأت الرياضية بالمدارس الخاصة بمحافظات شمال الصعيد من خلال:- - مي 
- زيادة دخل المدارس الخاصة من خلال استغلال المنشأت والإمكانات بصورة

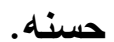

- تغطية نفقات المدربين والمعلمين والاداريين من خلال تسويق المنشأت ليصبح صرف ذاتي وليس عبئاً علي المنشأة. - اثباع حاجات المجتمع المحيط من ممارسة النشاط الرياضي . - زيادة عدد المستفيدين وإيجاد فرص عمل اكثر للمدربين والاداريين والمعلمين.

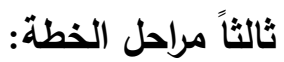

عند اعداد الأجزاء التفصيلية للخطة يمكن الفصل بين مرحلتين أساسيتين وهما مرحلة التحليل ومرحلة التصميم.

- مرحلة التحليل: وتشمل دراسة الواقع الفعلي للمدارس الخاصة وامكانياتها وقطاع العمل الخاص بها، (هذا ما قام به الباحثين).

- مرحلة التصميم: وتثمل دراسة الواقع الخاص بالمدارس ووضعها في المجتمع وإعطاء تفاصيل أكثر لسياساتها وميزانياتها،(قام ايضاً به الباحثين) - مرحلة التفيذ: البدء في تنفيذ الخطة علي ارض الواقع (وهذا ما يأمله الباحثين من وضع الدراسة في حيذ التفيذ من قبل المسئولين). رابعاً مرحلة تنفيذ الخطة (مقترح الباحثين):

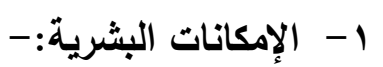

- وضع لوائح وقوانين تحفز وتشجع علي تسويق الإمكانات والمنشأت. - إضافة وظيفة مدير تسويق رياضي لتسويق الإمكانات والمنشأت الرياضية بالمدارس الخاصة. 
- الاستفادة من معلمي التربية الرياضية العاملين بالمدرسة مع اتاحة رواتب جديدة بما يتناسب مع أدائهم التدريبي. - تعيين مدربين في الأنشطة الرياضية المختلفة . - تعيين أو التعاقد مع شركة لصيانة الأجهزة والملاعب بشكل مستمر . - عقد دورات تدريبية بشكل مستمر للمعلمين والمدربين بما يسمح لهم لزيادة خبراتهم ويما يعود علي المنشأة بالنفع في جذب اكبر عدد من افراد المجتمع. - الاستفادة من كادر العلاج الطبيعي واخصائي الإصابات في استخدام منشأت المدرسة لعلاج الإصابات الرياضية والتأهيل الحركي والرياضي ويرسوم منافسة للمستشفيات والمراكز الخاصة.

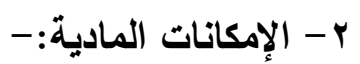

- تجديد وصيانة الأجهزة الموجوده بالمنشأة بشكل مستمر بما يضمن الحفاظ عليها وعدم هلكها.

- توفير عوامل الامن والسلامة بمفهومة الواسع لتجنب أثياء مثل الحوادث والامراض المعدية والكوارث الطبيعية. - العمل علي وضع خارطه تحديث لامكانات المدرسة وكيفية استغلالها بشكل دوري بما يضمن متابعه احتياجات المجتمع. ب- الاستفادة من التكنولوجيا الحديثة : - انشاء قاعدة بيانات للجمهور المستخدم للامكانات والمنشأت الرياضية بالمدرسة حتي تتمكن المدرسة من متابعتهم واعلامهم بكل جديد واطلاعهم علي عروض المدرسة. 
- تفعيل أو انثاء موقع الكتروني لتسويق الأنشطة الرياضية بالمدرسة بما يضمن سهولة الوصول للمجتمع واطلاع الافراد علي كل جديد.

- من الممكن تعاقد المدرسة مع مؤسسات طباعه أو صحيفة لعمل مطبوعات شهرياً لنشر ثقافة الممارسة الرياضية وتقديم معلومات رياضية باسم المدرسة هونة وايضاً التسويق المستمر لأنثطتها ما يعود بالنفع علي المدرسة في ترويج الإمكانات وأيضا الترويج لسمعه المدرسة. ع - تنظيم الفعاليات:-

- من الممكن تعاقد المدرسة مع جهات ومؤسسات ومصانع محيطه لاستغلال الملاعب والإمكانات في إقامة مسابقات بين العاملين. - التعاقد مع افرع الاتحادات لإيجار واستغلال الملاعب والإمكانات خارج اليوم الاراسي باجور رمزية. - - إقامة عروض ومهرجانات علي ملاعب المدرسة خارج اليوم الدراسي تتضمن عروض مختلفة كالكاراتية والجمباز والتمرينات الرياضية، ويمكن من خلالها استدعاء احد الرياضيين البارزين بما يضمن الترويج المستمر للأنثطة والإمكانات والمنشأت الرياضية. 
المراجع

"تخطيط استراتيجي مقترح لتسويق الرياضة - - - أحمد السيد متولي المدرسية" ، المجلة العلمية للتربية البدنية<smiles>[12NH]</smiles>

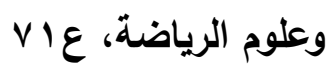

"استراتيجية مقترحة لتطوير الرياضة r

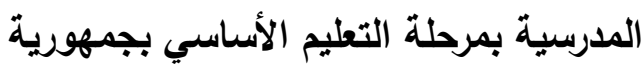
$(r \cdot 1 Y)$

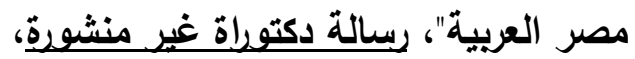
كلية التربية الرياضية، جامعة المنصورة "برنامج تربية رياضية مدرسية مطور كمصدر لتمويل مؤسسات التعليم قبل

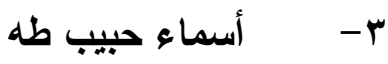
$\left(a^{r} \cdot 19\right)$ الجامعي"، رسالة دكتوراة غير منشورة، كلية التربية الرياضية، جامعة بني سويف "استراتيجيات التعليم نحو تدريس افضل"، ع - عبدالله مطر (r... مكتبة الفلاح، الكويت

"التسويق الرياضي وأهميته في تطوير أداء

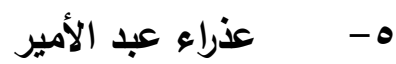
الأندية الرياضية العراقية ، رسالة دكتورلة $(r \cdot 1 \cdot)$

غير منشورة، جامعة بغداد، العرلق

"المقدمة في التسويق"، شركة الجمهورية

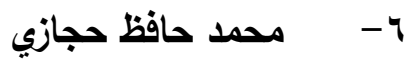
الحديثة للطباعة $(r \cdot . \varepsilon)$

"ترويج البطولات والمباريات الرياضية - - محمد رجب جبريل باستخدام المفهوم الحديث للتسويق"، رسالة $(r . .1)$

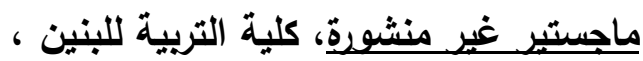
جامعة حلوان 
"مبادئ التسويث الحديث"، دار صفاء

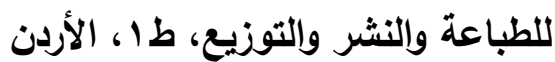

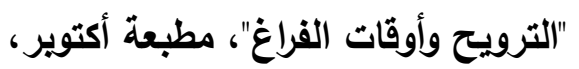

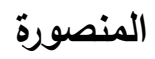

كتيب "اسأل تشارك في المدرسة المنتجة"

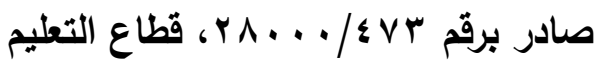

القتي الإدارة العامة للمدرسة المنتجة

$$
\begin{aligned}
& \text { ^- محمد قاسم القريوتي } \\
& (r . .1)
\end{aligned}
$$

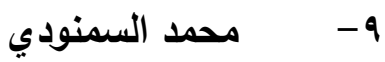

$$
\begin{aligned}
& (r, 1 r)
\end{aligned}
$$

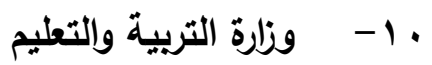

$(r \cdot r)$
Rockholz, Daria
Marie (,$\ldots$ r. $)$
Strategic Marketing for Public

Schools : A

Study of Implementation by

Connecticut Superintendents and

Assistant Superintendents .

University of Connecticut 